\title{
Changes in operant responding for saccharin in male and female hamsters following gonadectomy
}

\author{
H. E. MARKS \\ University of South Carolina, Lancaster, South Carolina 29720
}

\begin{abstract}
Male and female hamsters were trained to barpress for saccharin. Half of each group was gonadectomized and tested for response rate for saccharin reinforcement under water deprived and nondeprived conditions. Gonadectomized females did not differ from intact females in response rate or weight gain. Gonadectomized males gained more weight and barpressed less than intact males. These data were discussed as failing to support any current theory dealing with the effects of alterations in gonadal hormones on preference behavior.
\end{abstract}

Studies of the effects of alterations in sex hormones on nonsexual behaviors have focused on the rat. The enhanced preference for sweet solutions in female rats has generally been attributed to the actions of ovarian hormones on the female taste mechanism (Zucker, 1969; Zucker, Wade, \& Zeigler, 1972). However, questions have been raised about the role of sex hormones vs. body weight as factors determining saccharin preference (Marks, 1974a; Marks, Fargason, \& Hobbs, 1972; Marks \& Hobbs, 1972).

Studies using hamsters have also produced equivocal results. Marks (1974b) has suggested that the male hamster's saccharin preference. is modified by some correlate of body weight changes rather than directly by alterations in gonadal hormones. Zucker et al. (1972) was unable to find a reliable preference difference between intact and gonadectomized male hamsters but did find intact females had a small but statistically significantly greater saccharin preference than gonadectomized females (the same results found with rats). Gonadectomy produced no reliable weight differences in male body weight in Zucker et al.'s study, while Kowalewski (1969) reports greater increases in body weight in male hamsters following gonadectomy, and Marks (1974b) reports similar results in gonadectomized male hamsters fed Purina Lab Chow.

Both Zucker et al. (1972) and Marks (1974b) used 24-h liquid intake measures which tend to be quite variable. To reduce this source of variance, this experiment employed an operant response which also allowed each subject to serve as its own control.

This study was supported by a USC Faculty Research and Productive Scholarship grant. A part of this data was presented to the Southern Society for Philosophy and Psychology, 1975.

\section{METHOD}

Ten male and 10 female Syrian Golden hamsters (Mesocricetus auratus), 65-70 days old at the start of training, were used. The subjects were housed individually in plastic cages with free access to food. All training and testing was conducted in an LVE mouse-testing chamber with a liquid reinforcement system. Each subject was placed on a $22 \frac{1}{2} 2$-h water deprivation schedule 3 days prior to the initiation of magazine training.

The experiment was divided into four parts. The first part consisted of training the subjects to barpress on a fixed ratio of 10 responses per reinforcement (FR 10). The reinforcement was $.01 \mathrm{cc}$ of a $.1 \%(\mathrm{w} / \mathrm{v})$ saccharin solution. All training and testing sessions were $20 \mathrm{~min}$ in length and were followed by access to water for $1 \mathrm{~h}$.

Each subject was trained until it satisfied a criterion for stable performance. Stabilization was defined as a 5-day period in which the extreme scores of the subject were within the range of its 5 -day mean $\pm 10 \%$ of that mean. The hamsters were weighed each day prior to testing.

The same day a subject satisfied the criterion for stable performance, it was anesthetized with sodium pentobarbital (Nembutal, $90 \mathrm{mg} / \mathrm{kg}$ ) and either gonadectomized or subjected to a control operation. Surgery was done following the subject's 1-h access to water, with the actual time of surgery ranging from 3 to $51 / 2 \mathrm{~h}$ after that subject had completed its day's testing.

The day following surgery, Phase I was begun. Phase I was a replication of the FR 10 testing procedures employed in training with only one exception: the criterion for stabilization was increased to 10 days so that changes occurring over time would not be obscured by too short a testing period. When the subject had satisfied the Phase I stabilization criterion, it was maintained in its home cage with free access to both food and water for the following 15 days (Phase II). During Phase II, body weight was measured each day.

The day after the end of Phase II, the hamster was returned to the testing chamber and again tested for response rate for saccharin reinforcement on an FR 10 schedule (Phase III). Phase III differed from Phase I in only two respects: the subjects were not deprived, and a 5-day stabilization criterion was used. The stabilization criterion was returned to 5 days because the increased variability associated with the lack of deprivation made a 10-day stabilization period extremely difficult to achieve. 
Table 1

Stabilized Response Rates

\begin{tabular}{|c|c|c|c|c|}
\hline \multirow[b]{2}{*}{ Group } & \multirow{2}{*}{$\begin{array}{l}\text { Training } \\
\text { (Mean of } \\
5 \text { Days) }\end{array}$} & \multirow{2}{*}{$\begin{array}{l}\text { Phase } 1 \\
\text { (Mean of } \\
10 \text { Days) }\end{array}$} & \multicolumn{2}{|c|}{ Increase } \\
\hline & & & Amount & $\begin{array}{c}\text { Percen- } \\
\text { tage }\end{array}$ \\
\hline Male Operated & 1722.1 & 1868.3 & 146.2 & +7.41 \\
\hline Male Control & 1635.7 & 2351.3 & 715.6 & +45.75 \\
\hline Female Operated & 1516.8 & 1563.7 & 46.9 & +7.91 \\
\hline Female Control & 1711.3 & 1910.0 & 198.7 & +11.61 \\
\hline
\end{tabular}

\section{RESULTS}

Both male groups showed an increase in stabilized response rates from the end of training to Phase I (intact: $\mathrm{t}=13.74, \mathrm{df}=4, \mathrm{p}<.05 ; \mathbf{1}$ gonadectomized: $\mathrm{t}=7.08, \mathrm{df}=4, \mathrm{p}<.05)$, but only the gonadectomized females showed an increase in response rate $(t=4.73$, $\mathrm{df}=4, \mathrm{p}<.05)$. Comparisons of response rates across groups were statistically nonsignificant. The increase in response rates were greater for the intact than for the gonadectomized males (amount: $\mathrm{t}=2.90, \mathrm{df}=8$, $\mathrm{p}<.05 ;$ percentage: $\mathrm{t}=4.13, \mathrm{df}=8, \mathrm{p}<.05$ ), but differences in response changes were statistically nonsignificant for the female groups (see Table 1).

The results of the Phase III testing indicated that all groups greatly reduced response rates following the elimination of deprivation $(\mathrm{F}=8.66, \mathrm{df}=3 / 16, \mathrm{p}<.05$; see Table 2 ). No other comparisons were statistically significant.

The time required to stabilize response rates were not reliably different among any of the groups during either Phase I or Phase II (Table 3). However, a Mann-Whitney $\mathrm{U}$ test, comparing the change in days required to satisfy the stabilization criterion from Phase I to Phase III, indicated that the male groups required an increased number of days from Phase I to Phase III, while the female groups showed a decline in the number of days required $(\mathrm{U}=9, \mathrm{p}<.05)$.

Weight changes following surgery were very slow compared to those seen in rats (Table 4). Gonadectomized males gained more weight than intact males $(\mathrm{t}=3.82, \mathrm{df}=8, \mathrm{p}<.05)$, while differences between female groups were not statistically significant. Gonadectomized males gained more weight than intact females $(\mathrm{t}=2.47, \mathrm{df}=8, \mathrm{p}<.05)$, but not reliably more than gonadectomized females $(t=2.14, d f=8, p>.05)$.
Table 2

Stabilized Response Rates

\begin{tabular}{|c|c|c|c|c|c|}
\hline \multirow[b]{2}{*}{ Group } & \multirow{2}{*}{$\begin{array}{c}\text { Response } \\
\text { Rate } \\
\text { Phase 3* }\end{array}$} & \multicolumn{2}{|c|}{$\begin{array}{l}\text { Response Reduc. } \\
\text { tion Compared to }\end{array}$} & \multicolumn{2}{|c|}{$\begin{array}{c}\text { Percentage } \\
\text { Response Reduc- } \\
\text { tion Compared to }\end{array}$} \\
\hline & & Training & Phase 1 & Training & Phase 1 \\
\hline \multicolumn{6}{|l|}{ Male } \\
\hline $\begin{array}{l}\text { Operated } \\
\text { Control }\end{array}$ & $\begin{array}{l}483.6 \\
395.5\end{array}$ & $\begin{array}{l}1238.6 \\
1240.2\end{array}$ & $\begin{array}{l}1384.7 \\
1955.8\end{array}$ & $\begin{array}{l}-71.92 \\
-75.82\end{array}$ & $\begin{array}{l}-74.12 \\
-83.18\end{array}$ \\
\hline \multicolumn{6}{|l|}{ Female } \\
\hline $\begin{array}{l}\text { Operated } \\
\text { Control }\end{array}$ & $\begin{array}{l}621.2 \\
600.2\end{array}$ & $\begin{array}{r}895.6 \\
1111.1\end{array}$ & $\begin{array}{r}942.5 \\
1309.8\end{array}$ & $\begin{array}{l}-59.05 \\
-64.93\end{array}$ & $\begin{array}{l}-60.27 \\
-68.58\end{array}$ \\
\hline
\end{tabular}

*Mean of 5 days

\section{DISCUSSION}

Gonadectomized female rats show increased rates of weight gain and decreased saccharin preference compared to intact female rats, while gonadectomized male rats show slight decreases in rate of weight gain and slight increases in saccharin intake (Marks \& Hobbs, 1972; Zucker, 1969). The present study found no reliable weight or $r$ esponse rate for saccharin differences between intact and gonadectomized female hamsters but found that gonadectomized hamsters had a slower response rate for saccharin and a greater rate of weight gain than intact males. The results of Marks (1974b), as well as the results of this

Table 4

Body Weight Changes (in Grams/Day)

\begin{tabular}{lcccc}
\hline Group & Phase 1 & Phase 2 & Phase 3 & Total \\
\hline $\begin{array}{l}\text { Male } \\
\text { Operated }\end{array}$ & -0.075 & +1.574 & +0.686 & +0.814 \\
$\begin{array}{l}\text { Male } \\
\text { Control }\end{array}$ & +0.086 & +0.880 & +0.257 & +0.371 \\
$\begin{array}{l}\text { Female } \\
\begin{array}{l}\text { Operated } \\
\text { Female }\end{array}\end{array}$ & -0.111 & +0.867 & +0.720 & +0.450 \\
\begin{tabular}{l} 
Control \\
\hline
\end{tabular} & -0.032 & +1.067 & +0.579 & +0.476 \\
\hline
\end{tabular}

study, question the generality of the conclusion that saccharin preference changes are a direct result of alterations in the level of gonadal hormones (Zucker, 1969; Zucker et al., 1972). The conclusions that gonadal hormone alterations may produce different effects in different species (Zucker et al., 1972) was confirmed by this study.

It is questionable if any of the theoretical explanations presently available can adequately handle the data arising from the previously cited studies. The hypothesis of weigh-mediated behavioral changes (Marks, 1974b; Marks et al., 1972; Marks \& Hobbs, 1972) is not supported by this study. While a weight difference between intact and gonadectomized males was found,

Table 3

Days Required to Stabilize Response Rate

\begin{tabular}{|c|c|c|c|c|c|c|}
\hline \multirow[b]{2}{*}{ Group } & \multicolumn{2}{|c|}{ Phase 1} & \multicolumn{2}{|c|}{ Phase 3} & \multicolumn{2}{|c|}{ Total } \\
\hline & Range & Median & Range & Median & Range & Median \\
\hline Male Operated & $11-17$ & 12 & $10-22$ & 21 & $35-63$ & 49 \\
\hline Male Control & $12-18$ & 15 & $8-33$ & 28 & $41-60$ & 55 \\
\hline Female Operated & $15-37$ & 22 & $6-27$ & 16 & $35-70$ & 49 \\
\hline Female Control & $12-24$ & 20 & $8-30$ & 18 & $35-60$ & 55 \\
\hline
\end{tabular}


that weight difference was statistically significantly different only after Phase II; the obtained differences in response rate occurred only in Phase I.

The hypothesis that gonadal hormone alterations can reset the hypothalamic "lipostat," thus producing neurally mediated behavioral changes (Wade, 1972), is also unable to explain several experimental results. The lipostatic hypothesis receives direct support from data indicating increased proportions of body fat in gonadectomized female rats (Leshner \& Collier, 1973; Kibler, Mercer, \& Remley, Note 1). Preliminary data from my laboratory indicates similar results are found with male, but not female, hamsters. The problem with the hypothesis is that the variables producing the behavioral changes are not specified. Does a deviation from ideal weight (or adiposity) produce behavioral changes, or is the actual weight gain (increase in adiposity) responsible. If the former is chosen as the appropriate explanation, the results of the present study are predicted quite accurately: a behavioral difference exists only until the hamsters attain their new weight "set points," but most previously cited studies find behavioral differences continuing after the "set point" for weight has been attained. The latter explanation is not only not supported by the present study, but cannot explain several experiments in Marks (1974a). Whatever mechanisms mediate taste preference, they appear to be related to both weight and gonadal hormone levels, but apparently are not directly influenced by either one of these variables.

\section{REFERENCE NOTE}

1. Kibler, J. L., Mercer, L., \& Remley, N. R. The relationship between linear growth and body weight following ovariectomy in the rat. Paper presented at the Southern Society for Philosophy and Psychology, 1975.

\section{REFERENCES}

KowalewsKi, K., Effect of pre-pubertal gonadectomy and treatment with sex hormones on body growth, weight of organs, and skin collagen of hamsters. Acta Endocrinologica, 1973, 11, 671-676.

MARKs, H. E. Reactivity to different saccharin concentrations as a function of testing procedures and alterations in body weight of intact and oophorectomized female rats. Physiology and Behavior. 1974, 72, 29-38. (a)

MarKs, H. E. Body weight as a determinant of saccharin taste preferences in the orchidectomized male hamster (Mesocricetus auratus). Bulletin of the Psychonomic Society, 1974, 3, 11-13.(b)

Marks, H. E., Fargason, B. D., \&Hobbs, S. H. Reactivity to aversive stimuli as a function of body weight in normal and gonadectomized female rats. Physiology and Behavior, 1972, 9, 539-544.

MARKs, H. E., \& HoвBs, S. H. Changes in stimulus reactivity following gonadectomy in male and female rats of different ages. Physiology and Behavior, 1972, 8, 1113-1119.

WADE, G. N. Gonadal hormones and behavioral regulation of body weight. Physiology and Behavior, 1972, 8, 523-534.

ZUCKER, I. Hormonal determinants of sex differences in saccharin preference food intake and body weight. Physiology and Behavior, 1969, 4. 595-602.

Zucker, I., WADE, G. N., \& Ziegler, R. Sexual and hormonal influences on eating, taste preferences, and body weight of hamsters. Physiology and Behavior, 1972, 8, 101-111.

\section{NOTE}

1. An alpha level of .05 was selected, and all results are labeled as statistically significant at or beyond that level or statistically nonsignificant.

(Received for publication June 2, 1975.) 